\title{
Optimal radiotherapy for patients with internal mammary lymph node metastasis from breast cancer
}

\author{
Kyungmi Yang ${ }^{1}$, Haeyoung Kim² ${ }^{*}$ D, Doo Ho Choi ${ }^{2}$, Won Park², Jae Myoung Noh² and Won Kyung Cho ${ }^{2}$
}

\begin{abstract}
Background: This study aimed to determine the optimal radiotherapy (RT) regimen for patients with clinical metastasis to the internal mammary lymph node $(\mathrm{cIMN+})$ from breast cancer.

Methods: We retrospectively reviewed the medical records of 84 patients with cIMN+ breast cancer treated with curative surgery, taxane-based chemotherapy, and postoperative RT between January 2009 and December 2014. Postoperative RT was administered to the whole breast or chest wall using $50 \mathrm{~Gy}$ in $2 \mathrm{~Gy}$ fractions. Boost RT to the internal mammary lymph node (IMN) was administered at the physician's discretion. We categorized patients into two groups according to the IMN dose as follows: low-dose IMN RT (50.0-63.5 Gy) and high-dose IMN RT (63.6$70.4 \mathrm{~Gy})$.
\end{abstract}

Results: After a median follow-up of 58 months (range, 12-111 months), IMN recurrence was observed in 2 patients (2.4\%), and all IMN recurrences developed simultaneously with distant metastases. The 5-year locoregional recurrence-free survival, disease-free survival (DFS), and overall survival rates were 89.1, 72.0, and 81.2\%, respectively. The triple-negative subtype, IMN size $\geq 1.0 \mathrm{~cm}$, old age, and low-dose IMN were significantly associated with poor DFS. Among the patients with IMN size $\geq 1.0 \mathrm{~cm}$, the 5 -year DFS was significantly higher in those treated with high-dose IMN RT than in those treated with low-dose IMN RT (69.3\% vs. 33.3\%, $p=0.019)$.

Conclusions: IMN RT without IMN dissection resulted in favorable outcomes in cIMN+ breast cancer. For patients with a large IMN, a higher IMN radiation dose might be needed for disease control.

Keywords: Breast cancer, Internal mammalian lymph node, Radiotherapy, Regional irradiation

\section{Introduction}

Internal mammary node (IMN) involvement is a known poor prognostic factor for survival in patients with breast cancer. Patients with clinical IMN involvement (cIMN+) had a low survival rate with frequent distant metastasis compared to those without cIMN+ [1]. Previous surgical studies found that the frequency of pathologic IMN involvement was between 28 and $52 \%$ in patients with axillary lymph node (ALN) metastasis, while it was between 5 and $17 \%$ for patients without ALN metastasis [2,3]. According to recent studies in which contemporary imaging modalities such as computed tomography (CT), magnetic resonance imaging

\footnotetext{
* Correspondence: haeyoung0131.kim@samsung.com

${ }^{2}$ Department of Radiation Oncology, Samsung Medical Center,

Sungkyunkwan University School of Medicine, 81, Irwon-ro, Gangnam-gu,

Seoul, Republic of Korea 06351

Full list of author information is available at the end of the article
}

(MRI) or positron emission tomography-computed tomography (PET-CT) were performed, the incidence of cIMN+ ranged between 11 and $16 \%$ in breast cancer patients with advanced nodal disease (cN2-N3) $[4,5]$. Even though cIMN+ is frequently observed in patients with breast cancer, the optimal treatment method and prognosis have not been well identified.

In the past, radical mastectomy and IMN dissection were performed for patients with cIMN+, even though surgical treatment caused high morbidity without survival benefit [2]. In contrast, in recent years, multimodal treatments including breast surgery without IMN dissection, systemic therapy, and radiotherapy (RT) have been administered for patients with cIMN+ breast cancer. With these multimodal treatments, favorable outcomes could be achieved for cIMN+ breast cancer $[4,6]$. To 
eradicate the tumor in the IMN without node dissection, high-dose RT is presumably necessary. However, the optimal radiation dose has not been determined for patients with IMN+ breast cancer.

Therefore, we performed this study to evaluate the outcomes of combined treatment including breast surgery, systemic treatment, and IMN-targeted RT. Through this analysis, we aimed to determine the prognostic significance of radiation dose in achieving disease control in patients with cIMN+ breast cancer.

\section{Methods and materials}

We retrospectively reviewed medical records of patients who received postoperative RT for cIMN+ breast cancer at the Samsung Medical Center between January 2009 and December 2014. cIMN+ was defined as the IMN size of $\geq 0.5 \mathrm{~cm}$ on imaging studies at the time of breast cancer diagnosis. Imaging work-ups included chest CT, breast ultrasonography (US), breast MRI, or PET-CT. The size of the IMN was measured on breast MRI scans for all patients. Fine needle aspiration biopsy (FNABx) of the IMN was performed at the physician's decision when IMN metastasis was uncertain on imaging studies. The inclusion criteria for this study were as follows: 1) newly diagnosed cIMN+ breast cancer, 2) patients receiving curative surgery, taxane-based chemotherapy, and postoperative RT, 3) completion of planned RT, and 4) having no distant organ metastases. A total of 84 patients with cIMN+ were included in this analysis. Patients were staged according to the 7 th edition American Joint Committee on Cancer (AJCC) staging [7].

All patients underwent curative surgery including mastectomy or breast conserving surgery (BCS). Postoperative RT was administered to the whole breast or chest wall, supraclavicular lymph node (SCN), and the IMN, with a total dose of 50 Gy at 2 Gy per fraction. In patients who underwent BCS, a tumor bed boost was delivered after whole breast irradiation, using a total dose of 10-16 Gy at 2-3.5 Gy per fraction. Among 21 patients with SCN metastasis, an additional SCN dose of 6-15 Gy at 2-3 Gy per fraction was administered to 14 patients. Boost RT to the IMN was administered at the discretion of the attending physician, with a total dose of 6-16.5 Gy at 2-3.3 Gy per fraction. The total dose to the IMN was calculated using the biologically equivalent dose in 2 Gy fractions (EQD2) assuming the $\alpha / \beta$ ratio of $3.5 \mathrm{~Gy}[8]$. Patients were categorized according to the EQD2 of the IMN chain as follows: 1) 50-63.5 Gy, low-dose IMN RT, and 2) $\geq 63.6$ Gy, highdose IMN RT by using the Recursive partitioning procedure in R 2.2.1 ( $\mathrm{R}$ Development Core Team, Vienna, Austria, http://www.R-project.org). All patients underwent CT-simulation prior to RT. Three-dimensional conformal radiotherapy or intensity-modulated radiotherapy was performed in 82 patients and 2 patients, respectively. In radiotherapy planning, the bilateral lungs and heart were contoured as organs-at-risk (OAR). Dose-constraints for OAR were as follows: ipsilateral lung volume receiving 20 Gy or over $<30 \%$, heart volume receiving 17 Gy or over $<$ $10 \%$, and mean heart dose of $<5 \mathrm{~Gy}$.

Taxane-based chemotherapy was administered before or after surgery. Hormonal therapy or anti-human epidermal growth factor receptor type 2 (HER2) treatment was administered according to the tumor subtypes. Immunohistochemistry (IHC) of the breast tumors was performed for estrogen receptor (ER), progesterone receptor (PR), and HER2. Positivity of ER/PR was defined as an Allred score of 3 to 8 . HER2 positivity was defined as staining of $3+$ on IHC or $2+$ on IHC along with positive results on fluorescence in situ hybridization or silver in situ hybridization.

The loco-regional recurrence-free survival (LRRFS), progression-free survival (PFS), and overall survival (OS) were calculated between the time of primary treatment initiation and the date of locoregional recurrence, cancer recurrence, and death, respectively. The severity of treatment-related toxicity was graded according to the Common Terminology Criteria for Adverse Events (CTCAE) version 4.0 [9]. Kaplan-Meier survival analysis was performed to estimate the survival rates, and the log-rank test was used to compare survival between groups with different variables. Univariate and multivariate analyses using Cox regression models were used to evaluate the influence of variables on survival. Variables with significance at $p<0.3$ on univariate analysis were retained for multivariate analysis.

Values were considered statistically significant when $p<$ 0.05 . All statistical analyses were performed using SPSS Statistics version 22 (SPSS Inc., IBM, Chicago, IL, USA). This study was approved by the institutional review board of the Samsung Medical Center with No. 2019-02-081, and was classified exempt to obtain informed consent of the participants.

\section{Results}

\section{Patient characteristics}

Of 2114 patients who received postoperative radiotherapy for regional lymph node-positive breast cancer between 2009 and 2014, a total of 84 patients met the inclusion criteria for this study. The median age of patients was 41 years (range, 28-67 years). Most patients (92.9\%) had invasive ductal carcinoma. All 84 patients had cIMN+ involving a single intercostal space $(n=37)$ or extending to multiple intercostal spaces $(n=47)$. Breast MRI was performed for all patients. Breast US, chest CT, and PET-CT were performed for 83 patients, 67 patients, and 72 patients, respectively. The median long diameter of the IMN was $0.9 \mathrm{~cm}$ (range, 0.5-1.8 $\mathrm{cm})$. FNABx of the IMN was conducted for 43 patients 
at the time of breast cancer diagnosis. Among the 43 patients, 40 patients had a pathologically confirmed IMN metastasis.

Intensity-modulated RT was performed in 2 patients while conventional RT using partial wide tangent beams $(n=44)$ or photon-electron mixed fields $(n=38)$ were performed in 82 patients. Boost RT to the IMN region was applied for 69 patients after whole breast or chest wall irradiation. The median EQD2 to the IMN region was 63.6 Gy. A total of 35 patients $(41.7 \%)$ received $<63.6$ Gy to the IMN while 49 (58.5\%) patients underwent $\geq 63.6$ Gy EQD2 to the IMN chain. The patient characteristics are shown in Table 1. There was no significant difference in patient characteristics between the high-dose IMN RT group and the low-dose IMN RT group, except in the type of breast surgery (Table 2). More patients treated with mastectomy received high-dose radiation to the IMN compared to those treated with BCS (63.3\% vs. $36.7 \%, p=0.026)$.

\section{Patterns of failure, survival, and prognostic factors}

After a median follow-up time of 58 months (range, 12-111 months), 15 patients died and 26 showed recurrence. The IMN recurrence was developed in $2(2.4 \%)$ patients. All IMN recurrences were found simultaneously with distant metastases. One of the IMN recurrences was found in a patient who received $66 \mathrm{~Gy}$ of IMN irradiation, at 6 months after the completion of RT. The other IMN recurrence was noted after 16 months after the completion of RT in a patient who received 50 Gy of IMN RT. The sites of the first recurrence were as follows: loco-regional recurrence only, 2 patients; distant metastasis only, 15 patients; and simultaneous locoregional and distant recurrences, 9 patients. Among the 24 patients with distant metastases, the metastatic sites were as follows: non-regional lymph nodes only, 3 patients; visceral organs only, 6 patients; bone only, 6 patients; and simultaneous multi-organ involvement, 9 patients.

The 5-year LRRFS, DFS, and OS rates were 89.1, 72.0, and $81.2 \%$, respectively (Fig. 1). Among the clinical factors, patient age, tumor subtype, size of the IMN, and radiation dose to the IMN were significantly associated with DFS. Age $>40$ years, triple-negative breast cancer (TNBC) subtype, IMN size $\geq 1.0 \mathrm{~cm}$, and receiving IMN radiation dose <63.6 Gy were significantly associated with inferior DFS (Table 3). We compared patient DFS depending on the IMN size and IMN radiation dose. The patient characteristics were not significantly different depending on the size of the IMN (Table 4). The IMN radiation dose had a different prognostic significance depending on the IMN size. In patients with IMN size $\geq 1.0 \mathrm{~cm}$, high-dose IMN RT was significantly associated with better DFS compared to low-dose IMN RT (69.3\% vs. $33.3 \%, p=0.019$, Fig. 2b). However, in patients with IMN size $<1.0 \mathrm{~cm}$, DFS was not influenced by the IMN radiation dose (Table 5, Fig. 2a). TNBC subtype
Table 1 Patient characteristics

\begin{tabular}{|c|c|c|}
\hline Characteristics & & $\begin{array}{l}\text { Number of } \\
\text { patients (\%) }\end{array}$ \\
\hline \multirow[t]{2}{*}{ Age (years) } & $\leq 40$ & $38(45.2 \%)$ \\
\hline & $>40$ & $46(54.8 \%)$ \\
\hline \multirow[t]{2}{*}{ Laterality of breast cancer } & Left breast & $57(67.9 \%)$ \\
\hline & Right breast & $27(32.1 \%)$ \\
\hline \multirow[t]{2}{*}{ Location of breast cancer } & Inner or center part & $66(78.6 \%)$ \\
\hline & Outer part & $18(21.4 \%)$ \\
\hline \multirow[t]{2}{*}{ Histologic type } & Invasive ductal carcinoma & 78 (92.9\%) \\
\hline & Others & $6(7.1 \%)$ \\
\hline \multirow[t]{3}{*}{ Histologic grade } & $1-2$ & $45(53.6 \%)$ \\
\hline & 3 & $30(35.7 \%)$ \\
\hline & Unknown & $9(10.7 \%)$ \\
\hline \multirow[t]{4}{*}{ Tumor subtype } & ER+/or PR+/HER2- & $32(38.1 \%)$ \\
\hline & ER+/or PR+/HER2+ & $12(14.3 \%)$ \\
\hline & ER-/PR-/HER2+ & $10(11.9 \%)$ \\
\hline & ER-/PR-/HER2- & $30(35.7 \%)$ \\
\hline \multirow[t]{2}{*}{ cT stage } & $\mathrm{T} 1-\mathrm{T} 2$ & $47(56.0 \%)$ \\
\hline & T3-T4 & $37(44.0 \%)$ \\
\hline \multirow[t]{2}{*}{ cN stage } & $\mathrm{N} 2 \mathrm{~b}$ or N3b & $63(75.0 \%)$ \\
\hline & N3c & $21(25.0 \%)$ \\
\hline \multirow[t]{2}{*}{ Extent of IMN } & Single ICS & 37 (44.0\%) \\
\hline & Multiple ICS & 47 (56.0\%) \\
\hline \multirow[t]{2}{*}{ Long diameter of the IMN } & $<1.0 \mathrm{~cm}$ & $42(50.0 \%)$ \\
\hline & $\geq 1.0 \mathrm{~cm}$ & $42(50.0 \%)$ \\
\hline \multirow[t]{2}{*}{ Type of breast surgery } & Breast-conserving surgery & $40(47.6 \%)$ \\
\hline & Mastectomy & $44(52.4 \%)$ \\
\hline \multirow[t]{2}{*}{ Type of axillary surgery } & $\begin{array}{l}\text { Sentinel lymph node } \\
\text { biopsy }\end{array}$ & $10(11.9 \%)$ \\
\hline & $\begin{array}{l}\text { Axillary lymph node } \\
\text { dissection }\end{array}$ & $74(88.1 \%)$ \\
\hline \multirow[t]{2}{*}{ Neoadjuvant chemotherapy } & Performed & $66(78.6 \%)$ \\
\hline & Not performed & $18(21.4 \%)$ \\
\hline EQD2 of the IMN ${ }^{1)}$ & 50.0-63.5 Gy & $35(41.7 \%)$ \\
\hline $\begin{array}{l}\text { (median, 63.6 Gy; range, 50- } \\
\text { 70.4 Gy) }\end{array}$ & 63.6-70.4 Gy & 49 (58.3\%) \\
\hline
\end{tabular}

${ }^{1)}$ Radiotherapy dose was calculated using the EQD2 assuming the $\alpha / \beta$ ratio of 3.5 Gy. Abbreviations: IDC Invasive ductal carcinoma; $E R$ Estrogen receptor, $P R$ Progesterone receptor, HER2 Human epidermal growth factor receptor type 2, ICS Intercostal space, IMN Internal mammary node, EQD2 Biologically equivalent dose in $2 \mathrm{~Gy}$ fractions

was significantly associated with worse LRRFS in comparison to non-TNBC tumors (Table 6). Old age and TNBC subtype were significant factors linked to worse OS (Table 7).

\section{Treatment-related toxicity}

There were no cases of grade $\geq 3$ toxicity. Grade 2 toxicity was found in 6 patients: dermatitis in 4 patients, 
Table 2 Patient's characteristics according to radiation dose to internal mammary lymph node

\begin{tabular}{|c|c|c|c|c|}
\hline \multirow[t]{2}{*}{ Characteristics } & & \multicolumn{2}{|c|}{ Number of patients (\%) } & \multirow{2}{*}{$\begin{array}{l}p- \\
\text { value }\end{array}$} \\
\hline & & $50-63.5 \mathrm{~Gy}{ }^{1)}(n=35)$ & $63.6-70.4$ Gy ${ }^{1)}(n=49)$ & \\
\hline \multirow[t]{2}{*}{ Age } & $\leq 40$ years & $15(42.9 \%)$ & $23(46.9 \%)$ & \multirow[t]{2}{*}{0.825} \\
\hline & $>40$ years & $20(57.1 \%)$ & $26(53.1 \%)$ & \\
\hline \multirow[t]{2}{*}{ Histologic grade } & $1-2$ & $23(71.9 \%)$ & $22(51.2 \%)$ & \multirow[t]{2}{*}{0.096} \\
\hline & 3 & $9(28.1 \%)$ & $21(48.8 \%)$ & \\
\hline \multirow[t]{2}{*}{ Subtypes } & Non-TNBC & $22(62.9 \%)$ & $32(65.3 \%)$ & \multirow[t]{2}{*}{0.822} \\
\hline & TNBC & $13(37.1 \%)$ & $17(34.7 \%)$ & \\
\hline \multirow[t]{2}{*}{ CT stages } & $1-2$ & 19 (54.3\%) & $28(57.1 \%)$ & \multirow[t]{2}{*}{0.827} \\
\hline & $3-4$ & $16(45.7 \%)$ & $21(42.9 \%)$ & \\
\hline \multirow[t]{2}{*}{ CN stages } & $2 b$ or $3 b$ & $26(74.3 \%)$ & $37(75.5 \%)$ & \multirow[t]{2}{*}{1.000} \\
\hline & $3 c$ & $9(25.7 \%)$ & $12(24.5 \%)$ & \\
\hline \multirow[t]{2}{*}{ FNABx for IMN } & $(-)$ or unknown & $20(57.1 \%)$ & $24(49.0 \%)$ & \multirow[t]{2}{*}{0.511} \\
\hline & $(+)$ & $15(42.9 \%)$ & $25(51.0 \%)$ & \\
\hline \multirow[t]{2}{*}{ Extent of the IMN } & Single ICS & $13(37.1 \%)$ & $24(49.0 \%)$ & \multirow[t]{2}{*}{0.373} \\
\hline & Multiple ICS & $22(62.9 \%)$ & $25(51.0 \%)$ & \\
\hline \multirow[t]{2}{*}{ IMN long diameter } & $<1.0 \mathrm{~cm}$ & $20(57.1 \%)$ & $22(44.9 \%)$ & \multirow[t]{2}{*}{0.376} \\
\hline & $\geq 1.0 \mathrm{~cm}$ & $15(42.9 \%)$ & $27(55.1 \%)$ & \\
\hline \multirow[t]{2}{*}{ Neoadjuvant chemotherapy } & Not done & $9(25.7 \%)$ & $9(18.4 \%)$ & \multirow[t]{2}{*}{0.433} \\
\hline & Done & 26 (74.3\%) & 40 (81.6\%) & \\
\hline \multirow[t]{2}{*}{ Primary surgery } & BCS & 22 (62.9\%) & 18 (36.7\%) & \multirow[t]{2}{*}{0.026} \\
\hline & Mastectomy & $13(37.1 \%)$ & 31 (63.3\%) & \\
\hline \multirow[t]{2}{*}{ Axillary surgery } & ALND & 30 (85.7\%) & 44 (89.8\%) & \multirow[t]{2}{*}{0.735} \\
\hline & SLNB & 5 (14.3\%) & $5(10.2 \%)$ & \\
\hline
\end{tabular}

${ }^{1)}$ Radiotherapy dose was calculated using the biologically equivalent dose in $2 \mathrm{~Gy}$ fractions (EQD2) assuming the $\alpha / \beta$ ratio of $3.5 \mathrm{~Gy}$

Abbreviations: TNBC Triple-negative breast cancer, IMN Internal mammary node, FNABx Fine needle aspiration biopsy, ICS Intercostal space, BCS Breast conserving surgery, ALND Axillary lymph node dissection, SLNB Sentinel lymph node biopsy

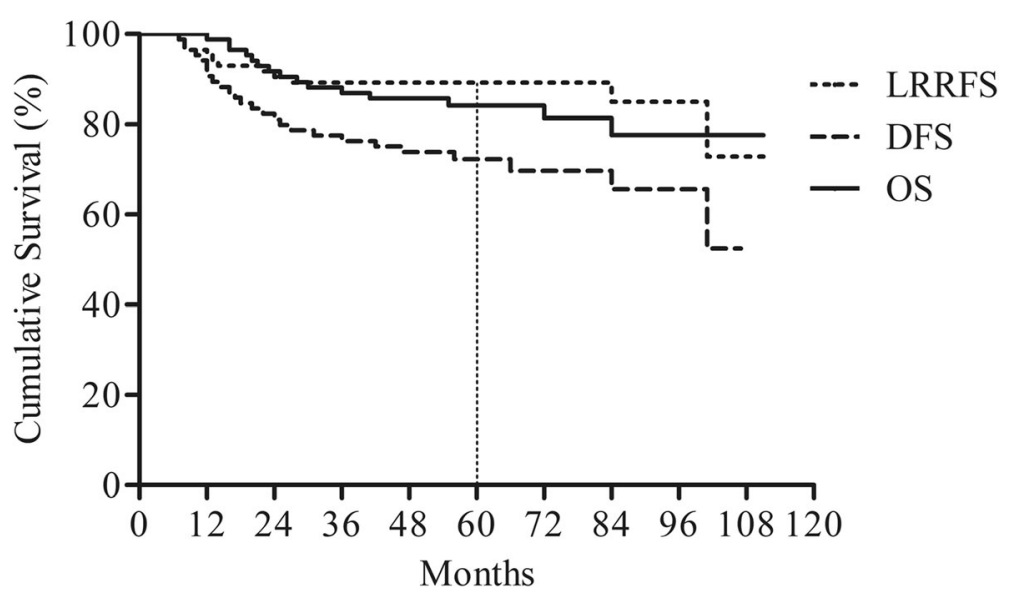

Fig. 1 Clinical outcomes of breast cancer patients with clinically positive IMN. Abbreviations: IMN, internal mammary node, LRRFS, Loco-Regional Recurrence-Free Survival; DFS, Disease-Free Survival; OS, Overall Survival 
Table 3 Prognostic factors of disease-free survival

\begin{tabular}{|c|c|c|c|c|c|}
\hline Characteristics & & 5-year DFS (\%) & $\begin{array}{l}\text { Univariate } \\
p \text {-value }\end{array}$ & $\begin{array}{l}\text { Multivariate } \\
p \text {-value }\end{array}$ & $\begin{array}{l}\text { HR } \\
(95 \% \mathrm{Cl})\end{array}$ \\
\hline \multirow[t]{2}{*}{ Age } & $\leq 40$ years $(n=38)$ & $85.5 \%$ & \multirow[t]{2}{*}{0.007} & \multirow[t]{2}{*}{0.012} & \multirow{2}{*}{$\begin{array}{l}0.301 \\
(0.118-0.767)\end{array}$} \\
\hline & $>40$ years $(n=46)$ & $60.7 \%$ & & & \\
\hline \multirow[t]{2}{*}{ Tumor subtype ${ }^{1)}$} & Non-TNBC $(n=54)$ & $80.7 \%$ & \multirow[t]{2}{*}{0.012} & \multirow[t]{2}{*}{$<0.001$} & \multirow{2}{*}{$\begin{array}{l}0.189 \\
(0.079-0.453)\end{array}$} \\
\hline & $\operatorname{TNBC}(n=30)$ & $56.7 \%$ & & & \\
\hline \multirow[t]{2}{*}{ CT stages } & $1-2(n=47)$ & $77.9 \%$ & \multirow[t]{2}{*}{0.090} & \multirow[t]{2}{*}{0.070} & \multirow{2}{*}{$\begin{array}{l}0.442 \\
(0.183-1.068)\end{array}$} \\
\hline & $3-4(n=37)$ & $64.8 \%$ & & & \\
\hline \multirow[t]{2}{*}{$\mathrm{CN}$ stages } & $2 b$ or $3 b(n=63)$ & $72.1 \%$ & \multirow[t]{2}{*}{0.576} & \multirow[t]{2}{*}{-} & \multirow[t]{2}{*}{-} \\
\hline & $3 c(n=21)$ & $71.4 \%$ & & & \\
\hline \multirow[t]{2}{*}{ Malignant cells on FNABx of the IMN } & $(-)$ or unknown $(n=44)$ & $73.7 \%$ & \multirow[t]{2}{*}{0.610} & \multirow[t]{2}{*}{-} & \multirow[t]{2}{*}{-} \\
\hline & $(+)(n=40)$ & $65.4 \%$ & & & \\
\hline \multirow[t]{2}{*}{ Extent of IMN } & Single ICS $(n=37)$ & $74.9 \%$ & \multirow[t]{2}{*}{0.525} & \multirow[t]{2}{*}{-} & \multirow[t]{2}{*}{-} \\
\hline & Multiple ICS $(n=47)$ & $63.4 \%$ & & & \\
\hline \multirow[t]{2}{*}{ IMN long diameter } & $<1.0 \mathrm{~cm}(n=42)$ & $87.9 \%$ & \multirow[t]{2}{*}{0.002} & \multirow[t]{2}{*}{$<0.001$} & \multirow{2}{*}{$\begin{array}{l}0.157 \\
(0.060-0.412)\end{array}$} \\
\hline & $\geq 1.0 \mathrm{~cm}(n=42)$ & $56.4 \%$ & & & \\
\hline \multirow[t]{2}{*}{ Neoadjuvant chemotherapy } & Performed $(n=66)$ & $72.1 \%$ & \multirow[t]{2}{*}{0.927} & \multirow[t]{2}{*}{-} & \multirow[t]{2}{*}{-} \\
\hline & Not performed $(n=18)$ & $71.1 \%$ & & & \\
\hline \multirow[t]{2}{*}{ Axillary surgery } & $\operatorname{ALND}(n=74)$ & $69.5 \%$ & \multirow[t]{2}{*}{0.184} & \multirow[t]{2}{*}{0.056} & \multirow{2}{*}{$\begin{array}{l}8.003 \\
(0.947-67.663)\end{array}$} \\
\hline & $\operatorname{SLNB}(n=10)$ & $90.0 \%$ & & & \\
\hline EQD2 of the $\mathrm{IMN}^{2)}$ & $50.0-63.5 \mathrm{~Gy}(n=35)$ & $65.1 \%$ & 0.188 & 0.029 & 2.491 \\
\hline & 63.6-70.4 Gy $(n=49)$ & $76.6 \%$ & & & \\
\hline
\end{tabular}

${ }^{1)}$ TNBC was defined as tumors that were negative for the estrogen receptor, progesterone receptor, and human epidermal growth factor receptor 2 on immunohistochemical staining of the breast tumor

${ }^{2)}$ Radiotherapy dose was calculated using the EQD2 assuming the $\alpha / \beta$ ratio of $3.5 \mathrm{~Gy}$

Abbreviations: DFS Disease-free survival, TNBC Triple-negative breast cancer, FNABx, fine needle aspiration biopsy, IMN Internal mammary node, ICS Intercostal space, ALND Axillary lymph node dissection, SLNB Sentinel lymph node biopsy; HR Hazard ratio; CI Confidence interval, EQD2 Biologically equivalent dose in 2 Gy fractions

pneumonitis in 1 patient, and cardiac disorder in 1 patient. Cardiac toxicity, presenting as diastolic dysfunction, was found 5 years after the completion of RT in a patient with left breast cancer. The patient had received 50 Gy of RT to the left chest wall, SCN, and IMN region. Medication for diastolic dysfunction was continued for 7 months. At the time of data collection for this study, the patient had no symptoms associated with the cardiac disease after medication.

\section{Discussion}

In patients with cIMN+ breast cancer, a combination of breast surgery, postoperative RT, and taxane-based chemotherapy resulted in favorable outcomes even without IMN dissection. Less than $3 \%$ of our patients had IMN recurrence after the combination treatment. Old age, TNBC, and large IMN were associated with poor DFS. In patients with a large IMN, the IMN radiation dose significantly affected the DFS. The EQD2 > 63.5 Gy was associated with improved DFS in patients with IMN size $\geq 1.0$ $\mathrm{cm}$. However, the association between IMN radiation dose and DFS was not significant in patients with IMN size < $1.0 \mathrm{~cm}$. Therefore, it might be necessary to modify the IMN radiation dose according to the size of the IMN during postoperative RT for cIMN+ breast cancer.

The IMN is situated in the parasternal region surrounded by the interpectoral muscle, fibrofatty tissue, and the internal mammary vessels [10]. As the IMN is located in narrow intercostal spaces adjacent to the internal mammary vessels, it is difficult to perform a biopsy the IMN. Even at the time of breast surgery, a separate incision might be needed to excise the IMN when BCS is performed for laterally located breast cancer [11]. According to a study, approximately $40 \%$ of patients with $\mathrm{cIMN}+$, diagnosed through imaging studies, had negative results on FNABx [12]. Over $80 \%$ of the FNABx-negativity was caused by sample inadequacy or poor visibility of the IMN. Likewise, pathologic confirmation of IMN status is not always feasible when IMN adenopathy is observed on imaging studies. Previous studies showed that the rate of pathologic confirmation of IMN metastasis ranged between 9 and 57\% in 
Table 4 Comparisons between patients with small internal mammary lymph nodes $(<1.0 \mathrm{~cm})$ and patients with large internal mammary lymph node $(\geq 1.0 \mathrm{~cm})$

\begin{tabular}{|c|c|c|c|c|}
\hline \multirow[t]{2}{*}{ Characteristics } & & \multicolumn{2}{|l|}{ Number of patients (\%) } & \multirow{2}{*}{$\begin{array}{l}p- \\
\text { value }\end{array}$} \\
\hline & & IMN size $<1.0 \mathrm{~cm},(n=42)$ & IMN size $\geq 1.0 \mathrm{~cm},(n=42)$ & \\
\hline \multirow[t]{2}{*}{ Age } & $\leq 40$ years & $20(47.6 \%)$ & $18(42.9 \%)$ & 0.827 \\
\hline & $>40$ years & $22(52.4 \%)$ & $24(57.1 \%)$ & \\
\hline \multirow[t]{2}{*}{ Histologic grade } & $1-2$ & $23(54.8 \%)$ & $22(52.4 \%)$ & 0.638 \\
\hline & 3 & $13(31.0 \%)$ & $17(40.5 \%)$ & \\
\hline \multirow[t]{2}{*}{ Subtypes ${ }^{1)}$} & Non-TNBC & $29(69.0 \%)$ & $25(59.5 \%)$ & 0.495 \\
\hline & TNBC & $13(31.0 \%)$ & $17(40.5 \%)$ & \\
\hline \multirow[t]{2}{*}{ CT stages } & $1-2$ & $23(54.8 \%)$ & $24(57.1 \%)$ & 1.000 \\
\hline & $3-4$ & 19 (45.2\%) & $18(42.9 \%)$ & \\
\hline \multirow[t]{2}{*}{$\mathrm{cN}$ stages } & $2 b$ or $3 b$ & $30(71.4 \%)$ & $33(78.6 \%)$ & 0.615 \\
\hline & $3 c$ & $12(28.6 \%)$ & $9(21.4 \%)$ & \\
\hline \multirow[t]{2}{*}{ Malignant cells on FNABx of the IMN } & (-) or unknown & $22(52.4 \%)$ & $22(52.4 \%)$ & 1.000 \\
\hline & $(+)$ & $20(47.6 \%)$ & $20(47.6 \%)$ & \\
\hline \multirow[t]{2}{*}{ Extent of IMN } & Single ICS & $20(47.6 \%)$ & $17(40.5 \%)$ & 0.661 \\
\hline & Multiple ICS & $22(52.4 \%)$ & $25(59.5 \%)$ & \\
\hline \multirow[t]{2}{*}{ Neoadjuvant chemotherapy } & Performed & 29 (69.0\%) & 37 (88.1\%) & 0.061 \\
\hline & Not performed & 13 (31.0\%) & $5(11.9 \%)$ & \\
\hline \multirow[t]{2}{*}{ Primary surgery } & $\mathrm{BCS}$ & $20(47.6 \%)$ & $20(47.6 \%)$ & 1.000 \\
\hline & Mastectomy & $22(52.4 \%)$ & 22 (52.4\%) & \\
\hline \multirow[t]{2}{*}{ Axillary surgery } & ALND & 39 (92.9\%) & 35 (83.3\%) & 0.313 \\
\hline & SLNB & $3(7.1 \%)$ & $7(16.7 \%)$ & \\
\hline \multirow[t]{2}{*}{ EQD2 of the $\mathrm{IMN}^{2)}$} & 50.0-63.5 Gy & $20(47.6 \%)$ & 15 (35.7\%) & 0.376 \\
\hline & 63.6-70.4 Gy & 22 (52.4\%) & 27 (64.3\%) & \\
\hline
\end{tabular}

${ }^{1)}$ TNBC was defined as tumors that were negative for estrogen receptor, progesterone receptor, and human epidermal growth factor receptor 2 on immunohistochemical staining of the breast tumor

${ }^{2)}$ Radiotherapy dose was calculated using the EQD2 assuming the $\alpha / \beta$ ratio of $3.5 \mathrm{~Gy}$

Abbreviations: IMN Internal mammary node; TNBC Triple-negative breast cancer, FNABX Fine needle aspiration biopsy, ICS Intercostal space, BCS Breast conserving surgery, ALND Axillary lymph node dissection, SLNB Sentinel lymph node biopsy, EQD2 Biologically equivalent dose in 2 Gy fractions

patients with cIMN+ breast cancer [4, 12, 13]. Given the difficulty in performing biopsy of the IMN, a diagnosis of IMN metastases is made based on radiologic findings in many clinical situations. Therefore, it is necessary to consider the radiologic features of the IMN in optimizing the management of cIMN+ breast cancer. Moreover, the RT regimen is needed to be modified according to characteristics of the IMN.

In previous studies, an IMN diameter of $0.5 \mathrm{~cm}$ or larger in breast MRI has been regarded as metastatic IMN $[4,14$, 15]. In a study where MRI findings of IMN were compared with surgically dissected IMN, the IMN of $\geq 0.5 \mathrm{~cm}$ was likely to have malignant cells in pathologic examination with 90.7\% accuracy, $93.3 \%$ sensitivity, and $89.3 \%$ specificity [15]. Similarly, in a study where IMN metastasis was determined based on pathologic evaluation or PET-CT finding, IMN short-axis length $\geq 0.4 \mathrm{~cm}$ was predictive of positive metastasis with $92.5 \%$ sensitivity and $84.2 \%$ specificity [14]. According to recent studies of physiologic IMN adenopathy incidentally found in healthy females undergoing screening breast MRI, the mean IMN diameter was $0.45 \mathrm{~cm}$ [16] or $0.4 \mathrm{~cm}$ [17]. Based on above-mentioned studies, we defined IMN $\geq 0.5 \mathrm{~cm}$ on imaging studies as clinically positive for metastasis in our study. Considering that the size criterion for positive metastasis is generally regarded as $0.9-1.0 \mathrm{~cm}$ for axillary lymph node $[18,19]$, the size criterion of IMN metastasis is thought to be smaller than that of axillary lymph node metastasis.

IMN dissection had been used for the treatment of cIMN+ breast cancer. In a randomized controlled trial comparing the outcome between radical mastectomy and extended radical mastectomy including IMN dissection, locoregional control was better with IMN dissection. However, patient's overall survival and disease-free survival were not affected by the addition of IMN dissection [2]. Furthermore, other trials conducted before the 1980s reported that IMN dissection was not associated with improved survival in patients with breast cancer [20,21]. To perform IMN 


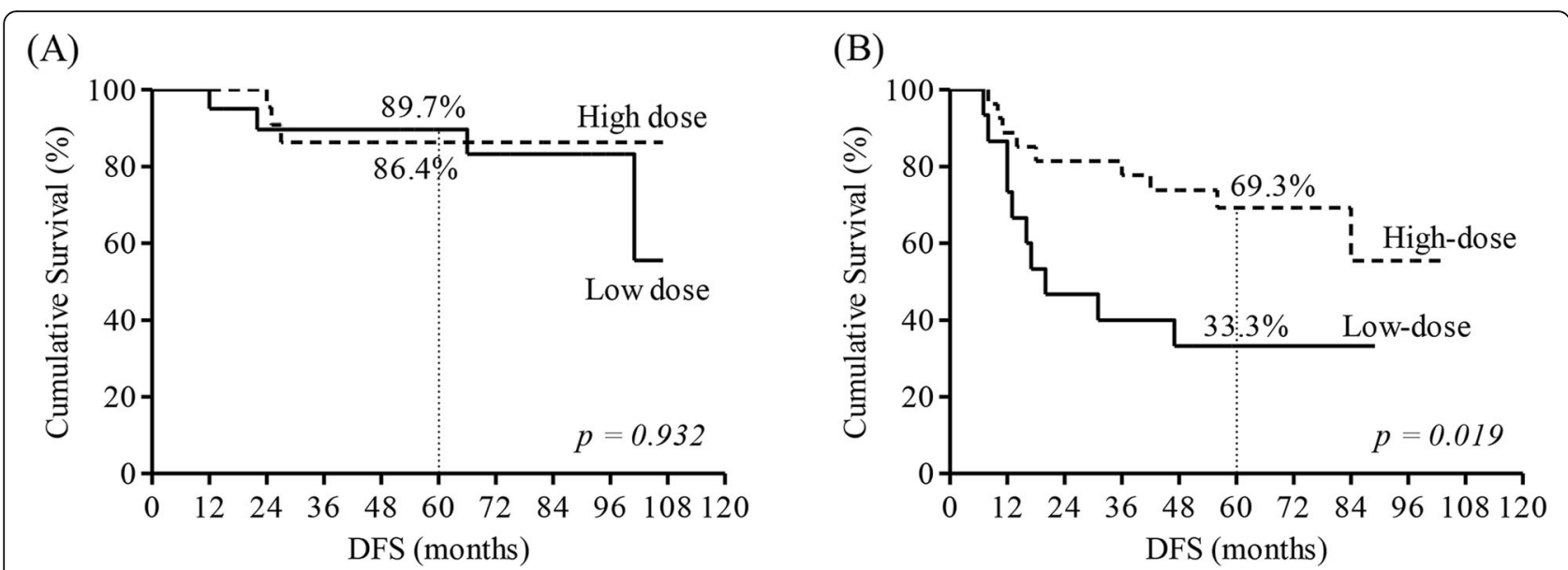

Fig. 2 Disease-free survival according to the internal mammary lymph node size and radiation dose to the internal mammary lymph node (a) In patients with the internal mammary lymph node size $<1.0 \mathrm{~cm}(n=42)$. (b) In patients with the internal mammary lymph node size $\geq 1.0 \mathrm{~cm}(n=$ 42). "Radiation dose to the IMN was grouped as follows: $50 \mathrm{~Gy}-63.5 \mathrm{~Gy}$, low-dose; and $\geq 63.6 \mathrm{~Gy}$, high-dose

dissection, additional skin incisions and chest tube placement might be necessary. In addition, division of intercostal muscle and transection of the ribs are also needed during surgery for IMN dissection [11]. Given the absence of a survival benefit and the possibility of surgical morbidity, surgical dissection of the IMN was abandoned [20,21]. Currently, a combination of breast surgery, systemic therapy, and RT encompassing the IMN is a common approach for treating cIMN+ breast cancer. With the introduction of effective systemic therapy such as chemotherapy, anti-hormonal therapy, or targeted therapy, the oncologic outcomes have improved in patients with breast cancer [22, 23]. In addition, advanced RT techniques enable precise targeting of the tumor, thereby allowing sufficient irradiation of the IMN region [24]. Such

Table 5 Disease-free survival according to the size of the internal mammary lymph node

\begin{tabular}{|c|c|c|c|c|c|}
\hline \multirow[t]{2}{*}{ Characteristics } & & \multicolumn{2}{|c|}{ IMN size $<1.0 \mathrm{~cm}(n=42)$} & \multicolumn{2}{|c|}{ IMN size $\geq 1.0 \mathrm{~cm}(n=42)$} \\
\hline & & 5-year DFS & $p$-value & 5-year DFS & $p$-value \\
\hline \multirow[t]{2}{*}{ Age } & $\leq 40$ years & $100.0 \%$ & 0.009 & $71.3 \%$ & 0.131 \\
\hline & $>40$ years & $77.3 \%$ & & $45.1 \%$ & \\
\hline \multirow[t]{2}{*}{ Subtypes ${ }^{11}$} & Non-TNBC & $96.4 \%$ & 0.031 & $63.5 \%$ & 0.120 \\
\hline & TNBC & $69.2 \%$ & & $47.1 \%$ & \\
\hline \multirow[t]{2}{*}{ CT stages } & $1-2$ & $91.1 \%$ & 0.267 & $65.2 \%$ & 0.119 \\
\hline & $3-4$ & $84.2 \%$ & & $44.4 \%$ & \\
\hline \multirow[t]{2}{*}{ cN stages } & $2 b$ or $3 b$ & $89.7 \%$ & 0.118 & $56.4 \%$ & 0.847 \\
\hline & $3 c$ & $83.3 \%$ & & $55.6 \%$ & \\
\hline \multirow[t]{2}{*}{ Malignant cells on FNABx of the IMN } & $(-)$ or & $86.5 \%$ & 0.327 & $54.5 \%$ & 0.930 \\
\hline & $\begin{array}{l}\text { unknown } \\
(+)\end{array}$ & $89.7 \%$ & & $58.7 \%$ & \\
\hline \multirow[t]{2}{*}{ Extent of IMN } & Single ICS & $90.0 \%$ & 0.899 & $57.0 \%$ & 0.658 \\
\hline & Multiple ICS & $85.9 \%$ & & $56.0 \%$ & \\
\hline \multirow[t]{2}{*}{ Neoadjuvant chemotherapy } & Not performed & $83.3 \%$ & 0.852 & $40.0 \%$ & 0.417 \\
\hline & Performed & $89.7 \%$ & & $58.5 \%$ & \\
\hline \multirow[t]{2}{*}{ EQD2 of the $\mathrm{IMN}^{2)}$} & 50.0-63.5 Gy & $89.7 \%$ & 0.932 & $33.3 \%$ & 0.019 \\
\hline & 63.6-70.4 Gy & $86.4 \%$ & & $69.3 \%$ & \\
\hline
\end{tabular}

${ }^{11}$ TNBC was defined as tumors that were negative for estrogen receptor, progesterone receptor, and human epidermal growth factor receptor 2 on immunohistochemical staining of the breast tumor

${ }^{2)}$ Radiotherapy dose was calculated using the EQD2 assuming the $\alpha / \beta$ ratio of $3.5 \mathrm{~Gy}$

Abbreviations: IMN Internal mammary node, DFS Disease-free survival, TNBC Triple-negative breast cancer, FNABx Fine needle aspiration biopsy, ICS Intercostal space, EQD2 Biologically equivalent dose in 2 Gy fractions 
Table 6 Prognostic factors of locoregional-recurrence free survival

\begin{tabular}{|c|c|c|c|c|c|}
\hline Characteristics & & 5-year LRRFS & $\begin{array}{l}\text { Univariate } \\
p \text {-value }\end{array}$ & $\begin{array}{l}\text { Multivariate } \\
p \text {-value }\end{array}$ & $\begin{array}{l}\mathrm{HR} \\
(95 \% \mathrm{Cl})\end{array}$ \\
\hline \multirow[t]{2}{*}{ Age } & $\leq 40$ years $(n=38)$ & $94.7 \%$ & 0.184 & 0.187 & $0.397(0.010-1.564)$ \\
\hline & $>40$ years $(n=46)$ & $84.3 \%$ & & & \\
\hline \multirow[t]{2}{*}{ Tumor subtype ${ }^{1)}$} & Non-TNBC $(n=54)$ & $96.3 \%$ & 0.009 & 0.004 & $0.120(0.029-0.500)$ \\
\hline & $\operatorname{TNBC}(n=30)$ & $75.8 \%$ & & & \\
\hline \multirow[t]{2}{*}{ CT stages } & $1-2(n=47)$ & $87.1 \%$ & 0.568 & - & - \\
\hline & $3-4(n=37)$ & $91.7 \%$ & & & \\
\hline \multirow[t]{2}{*}{ CN stages } & $2 \mathrm{~b}$ or $3 \mathrm{~b}(n=63)$ & $88.7 \%$ & 0.915 & - & - \\
\hline & $3 c(n=21)$ & $90.2 \%$ & & & \\
\hline \multirow[t]{2}{*}{ Malignant cells on FNABx of the IMN } & $(-)$ or unknown $(n=44)$ & $89.8 \%$ & 0.961 & - & - \\
\hline & $(+)(n=40)$ & $88.5 \%$ & & & \\
\hline \multirow[t]{2}{*}{ Extent of IMN } & Single ICS $(n=37)$ & $89.0 \%$ & 0.660 & - & - \\
\hline & Multiple ICS ( $n=47)$ & $89.2 \%$ & & & \\
\hline \multirow[t]{2}{*}{ IMN long diameter } & $<1.0 \mathrm{~cm}(n=42)$ & $92.5 \%$ & 0.267 & 0.129 & $0.365(0.099-1.330)$ \\
\hline & $\geq 1.0 \mathrm{~cm}(n=42)$ & $85.7 \%$ & & & \\
\hline \multirow[t]{2}{*}{ Neoadjuvant chemotherapy } & Performed $(n=66)$ & $92.3 \%$ & 0.108 & 0.167 & $0.242(0.034-1.626)$ \\
\hline & Not performed $(n=18)$ & $77.0 \%$ & & & \\
\hline \multirow[t]{2}{*}{ Axillary surgery } & $\operatorname{ALND}(n=74)$ & $88.9 \%$ & 0.889 & - & - \\
\hline & $\operatorname{SLNB}(n=10)$ & $90.0 \%$ & & & \\
\hline \multirow[t]{2}{*}{ EQD2 of the $\mathrm{IMN}^{2}$ ) } & 50.0-63.5 Gy $(n=35)$ & $85.5 \%$ & 0.544 & - & - \\
\hline & 63.6-70.4 Gy $(n=49)$ & $91.7 \%$ & & & \\
\hline
\end{tabular}

${ }^{11}$ TNBC was defined as tumors that were negative for the estrogen receptor, progesterone receptor, and human epidermal growth factor receptor 2 on immunohistochemical staining of the breast tumor

${ }^{2)}$ Radiotherapy dose was calculated using the EQD2 assuming the $\alpha / \beta$ ratio of $3.5 \mathrm{~Gy}$

Abbreviations: LRRFS Locoregional-recurrence free survival, TNBC Triple-negative breast cancer; FNABx Fine needle aspiration biopsy, IMN Internal mammary node, ICS Intercostal space, ALND Axillary lymph node dissection; SLNB Sentinel lymph node biopsy, HR Hazard ratio, $C l$ confidence interval, EQD2 Biologically equivalent dose in 2 Gy fractions

advances in the treatment of breast cancer have resulted in favorable tumor control in patients with cIMN+ breast cancer. There have been studies that reported the outcomes of multimodal treatments without IMN dissection for cIMN+ breast cancer (Table 8) [4, 12, 25-28]. The IMN control rate was excellent, with an IMN recurrence rate of $0-11 \%$ after multimodal treatments. The 5-year DFS rate was $56-72 \%$ in the studies. Similarly, in our study, we found excellent IMN control (crude rate of 97.6\%) and favorable DFS (72\% at 5 years) after combined modality treatment for cIMN+ breast cancer. Therefore, it is more appropriate to administer a combination treatment including IMN-targeting RT and systemic therapy rather than IMN dissection for patients with cIMN+ breast cancer.

IMN-targeting RT is essential for treating cIMN+ breast cancer; however, there have been few studies evaluating optimal radiation dose for cIMN+ breast cancer. A radiation dose of 45-50 Gy to the whole breast or chest wall plus a radiation boost to gross lesions has been recommended as a general guideline for postoperative RT for breast cancer [29]. For eradicating the gross tumor in the IMN, boost irradiation with 6-16 Gy has been administered to the IMN region in previous studies $[4,12,25-28]$. Accordingly, the median radiation dose to the IMN was 50.0-63.6 Gy in the previous studies. In our study, the median IMN dose was slightly higher compared to that in other studies. Moreover, a higher IMN radiation dose tended to be administered to patients with IMN size $\geq 1.0 \mathrm{~cm}$ compared to those with IMN size $<1.0 \mathrm{~cm}$. These RT regimens are probably associated with a favorable IMN control in our study.

We noted a significant influence of the IMN dose on DFS in the current study. A higher IMN dose was closely associated with better DFS. Nonetheless, the dose-response effect was evident only in patients with IMN size $\geq 1.0 \mathrm{~cm}$ and not in those with IMN size $<1.0 \mathrm{~cm}$. The 5 -year DFS in patients with IMN size $<1.0 \mathrm{~cm}$ was high (86.4-89.7\%), irrespective of the IMN RT dose. However, among the patients with IMN size $\geq 1.0 \mathrm{~cm}$, the 5-year DFS rate was only $33.3 \%$ after low-dose IMN RT while it was $69.3 \%$ after high-dose IMN $\mathrm{RT}$. The difference in the influence of the radiation dose depending on the IMN size might be owing to the IMN tumor 
Table 7 Prognostic factors of overall survival

\begin{tabular}{|c|c|c|c|c|c|}
\hline Characteristics & & 5-year OS & $\begin{array}{l}\text { Univariate } \\
p \text {-value }\end{array}$ & $\begin{array}{l}\text { Multivariate } \\
p \text {-value }\end{array}$ & $\begin{array}{l}\mathrm{HR} \\
(95 \% \mathrm{Cl})\end{array}$ \\
\hline \multirow[t]{2}{*}{ Age } & $\leq 40$ years $(n=38)$ & $94.6 \%$ & 0.007 & 0.009 & $0.132(0.029-0.609)$ \\
\hline & $>40$ years $(n=46)$ & $75.4 \%$ & & & \\
\hline \multirow[t]{2}{*}{ Tumor subtype ${ }^{1)}$} & Non-TNBC $(n=54)$ & $92.0 \%$ & 0.016 & 0.003 & $0.167(0.051-0.548)$ \\
\hline & TNBC $(n=30)$ & $70.0 \%$ & & & \\
\hline \multirow[t]{2}{*}{ cT stages } & $1-2(n=47)$ & $87.0 \%$ & 0.232 & 0.067 & $3.049(0.925-10.054)$ \\
\hline & $3-4(n=37)$ & $80.1 \%$ & & & \\
\hline \multirow[t]{2}{*}{ cN stages } & $2 b$ or $3 b(n=63)$ & $83.3 \%$ & 0.492 & - & - \\
\hline & $3 c(n=21)$ & $85.7 \%$ & & & \\
\hline \multirow[t]{2}{*}{ Malignant cells on FNABX of the IMN } & $(-)$ or unknown $(n=44)$ & $84.5 \%$ & 0.557 & - & - \\
\hline & $(+)(n=40)$ & $83.4 \%$ & & & \\
\hline \multirow[t]{2}{*}{ Extent of IMN } & Single ICS $(n=37)$ & $89.1 \%$ & 0.045 & 0.845 & $0.890(0.275-2.880)$ \\
\hline & Multiple ICS $(n=47)$ & $79.9 \%$ & & & \\
\hline \multirow[t]{2}{*}{ IMN long diameter } & $<1.0 \mathrm{~cm}(n=42)$ & $92.7 \%$ & 0.053 & 0.052 & $1.621(0.318-8.255)$ \\
\hline & $\geq 1.0 \mathrm{~cm}(n=42)$ & $75.7 \%$ & & & \\
\hline \multirow[t]{2}{*}{ Neoadjuvant chemotherapy } & Performed $(n=66)$ & $82.9 \%$ & 0.493 & - & - \\
\hline & Not performed $(n=18)$ & $87.8 \%$ & & & \\
\hline \multirow[t]{2}{*}{ Axillary surgery } & $\operatorname{ALND}(n=74)$ & $83.2 \%$ & 0.556 & - & - \\
\hline & $\operatorname{SLNB}(n=10)$ & $90.0 \%$ & & & \\
\hline \multirow[t]{2}{*}{ EQD2 of the IMN²) } & $50.0-63.5 \mathrm{~Gy}(n=35)$ & $85.3 \%$ & 0.926 & - & - \\
\hline & 63.6-70.4 Gy $(n=49)$ & $82.8 \%$ & & & \\
\hline
\end{tabular}

${ }^{1)}$ TNBC was defined as tumors that were negative for the estrogen receptor, progesterone receptor, and human epidermal growth factor receptor 2 on immunohistochemical staining of the breast tumor

${ }^{2)}$ Radiotherapy dose was calculated using the EQD2 assuming the $\alpha / \beta$ ratio of $3.5 \mathrm{~Gy}$

Abbreviations: OS Overall survival, TNBC Triple-negative breast cancer, FNABX Fine needle aspiration biopsy, IMN Internal mammary node, ICS Intercostal space, ALND Axillary lymph node dissection, SLNB Sentinel lymph node biopsy, HR Hazard ratio, CI Confidence interval, EQD2 Biologically equivalent dose in 2 Gy fractions

Table 8 Summary of studies in which multimodal treatment was performed without dissection of the internal mammary lymph node for patients with breast cancer and internal mammary lymph node metastases

\begin{tabular}{|c|c|c|c|c|c|c|c|}
\hline Authors & $\begin{array}{l}\text { No. of } \\
\text { patients }\end{array}$ & $\begin{array}{l}\text { Median FU } \\
\text { (months) }\end{array}$ & $\begin{array}{l}\text { Pathologic confirmation } \\
\text { of IMN+ }\end{array}$ & $\begin{array}{l}\text { Chemotherapy } \\
\text { regimen }\end{array}$ & $\begin{array}{l}\text { Median IMN RT dose, } \\
\text { (range) }\end{array}$ & $\begin{array}{l}\mathrm{IMN} \\
\text { recurrence }\end{array}$ & $\begin{array}{l}5 \text {-year survival } \\
\text { rates }\end{array}$ \\
\hline Zhang et al. (4) & 96 & 41 & $9 \%$ & AT-based (100\%) & 60.0 Gy (50.0-72.0 Gy) & $11 \%$ & $\begin{array}{l}\text { DFS } 56 \%, \text { OS } \\
76 \%\end{array}$ \\
\hline Park et al. $(25)^{1)}$ & 15 & 38 & $0 \%$ & $\begin{array}{l}\text { T-based (73\%), A-based } \\
(20 \%)\end{array}$ & 50.4 Gy (50.4-55.8 Gy) & $6.7 \%$ & $\begin{array}{l}\text { DFS } 67 \%, \text { OS } \\
79 \%\end{array}$ \\
\hline Noh et al. $(26)^{1)}$ & 45 & 57 & $40 \%$ & AT (54.5\%), AC (29.1\%) & 50.0-50.4 Gy +/- boost & $0 \%$ & $\begin{array}{l}\text { DFS 66\%, OS } \\
76 \%\end{array}$ \\
\hline Joo et al. (12) & 70 & 51 & $57 \%$ & T-based (94\%) & 60.0 Gy (56.0-66.0 Gy) & $2.9 \%$ & $\begin{array}{l}\text { DFS } 72 \%, \text { OS } \\
77 \%\end{array}$ \\
\hline $\begin{array}{l}\text { Sachdev et al. } \\
\text { (27) }\end{array}$ & 25 & 38 & Not reported & Not reported & 50.4 Gy (45.0-64.4 Gy) & $0 \%$ & Not reported \\
\hline Kim et al. (28) & 95 & 43 & $2 \%$ & Not reported & $\begin{array}{l}50.0 \text { Gy }+/- \text { boost }(n= \\
12)\end{array}$ & $3.2 \%$ & $\begin{array}{l}\text { DFS } 70 \%, \text { OS } \\
84 \%\end{array}$ \\
\hline $\begin{array}{l}\text { The present } \\
\text { study }\end{array}$ & 84 & 58 & $48 \%$ & T-based (100\%) & 62.5 Gy (50.0-66.5 Gy) & $2.4 \%$ & $\begin{array}{l}\text { DFS } 72 \%, \text { OS } \\
81 \%\end{array}$ \\
\hline
\end{tabular}

${ }^{1)}$ The studies included patients with internal mammary lymph node or supraclavicular lymph node metastasis from breast cancer Abbreviations FU Follow-up, IMN+ Metastasis to the internal mammary lymph node, IMN Internal mammary node, RT Radiotherapy, $A$ Adriamycini, $T$ Taxane, DFS Disease-free survival, OS Overall survival 
Table 9 Patient's characteristics according to age groups

\begin{tabular}{|c|c|c|c|c|}
\hline \multirow[t]{2}{*}{ Characteristics } & & \multicolumn{2}{|c|}{ Number of patients (\%) } & \multirow[t]{2}{*}{$p$-value } \\
\hline & & $\begin{array}{l}\leq 40 \text { years } \\
(n=38)\end{array}$ & $>40$ years $(n=46)$ & \\
\hline Follow-up duration & Median months (range) & 58.5 mo (15-111) & 59.0 mo (12-104) & $0.215^{1)}$ \\
\hline \multirow[t]{2}{*}{ Histologic grade } & $1-2$ & 22 (57.9\%) & $23(50.0 \%)$ & 0.163 \\
\hline & 3 & $10(26.3 \%)$ & $20(43.5 \%)$ & \\
\hline \multirow[t]{2}{*}{ Subtypes } & Non-TNBC & $25(65.8 \%)$ & 29 (63.0\%) & 0.974 \\
\hline & TNBC & $13(34.2 \%)$ & $17(37.0 \%)$ & \\
\hline \multirow[t]{2}{*}{ CT stages } & $1-2$ & $27(71.1 \%)$ & $28(60.9 \%)$ & 0.916 \\
\hline & $3-4$ & $11(28.9 \%)$ & $18(39.1 \%)$ & \\
\hline \multirow[t]{2}{*}{ CN stages } & $2 b$ or $3 b$ & $27(71.1 \%)$ & $36(78.3 \%)$ & 0.613 \\
\hline & $3 c$ & $11(28.9 \%)$ & $10(21.7 \%)$ & \\
\hline \multirow[t]{2}{*}{ FNABx for IMN } & $(-)$ or unknown & $16(42.1 \%)$ & 28 (60.9\%) & 0.135 \\
\hline & $(+)$ & $22(57.9 \%)$ & $18(39.1 \%)$ & \\
\hline \multirow[t]{2}{*}{ Extent of the IMN } & Single ICS & $18(47.4 \%)$ & 19 (41.3\%) & 0.737 \\
\hline & Multiple ICS & $20(52.6 \%)$ & 27 (58.7\%) & \\
\hline \multirow[t]{2}{*}{ IMN long diameter } & $<1.0 \mathrm{~cm}$ & $20(52.6 \%)$ & $22(47.8 \%)$ & 0.826 \\
\hline & $\geq 1.0 \mathrm{~cm}$ & $18(47.4 \%)$ & $24(52.2 \%)$ & \\
\hline \multirow[t]{2}{*}{ Neoadjuvant chemotherapy } & Not done & $7(18.4 \%)$ & $11(23.9 \%)$ & 0.731 \\
\hline & Done & $31(81.6 \%)$ & $35(76.1 \%)$ & \\
\hline \multirow[t]{2}{*}{ Primary surgery } & BCS & $20(52.6 \%)$ & $20(43.5 \%)$ & 0.538 \\
\hline & Mastectomy & $18(47.4 \%)$ & $26(56.5 \%)$ & \\
\hline \multirow[t]{2}{*}{ Axillary surgery } & ALND & 32 (84.2\%) & 42 (91.3\%) & 0.509 \\
\hline & SLNB & $6(15.8 \%)$ & 4 (8.7\%) & \\
\hline \multirow[t]{2}{*}{ RT dose to IMN ${ }^{2)}$} & 50-63.5 Gy & 15 (39.5\%) & $20(43.5 \%)$ & 0.882 \\
\hline & 63.6-70.4 Gy & $23(60.5 \%)$ & 26 (56.5\%) & \\
\hline
\end{tabular}

${ }^{1)}$ By the Mann-Whitney U-test

2) Radiotherapy dose was calculated using the biologically equivalent dose in 2 Gy fractions (EQD2) assuming the $\alpha / \beta$ ratio of $3.5 \mathrm{~Gy}$

Abbreviations: mo Months, TNBC Triple-negative breast cancer, IMN Internal mammary node, FNABx Fine needle aspiration biopsy, ICS Intercostal space, BCS Breast conserving surgery, ALND Axillary lymph node dissection, SLNB Sentinel lymph node biopsy

burden. In patients with the IMN $<1.0 \mathrm{~cm}$, there's thought to be small IMN tumor burden, which can be eradicated with moderate dose RT and systemic treatments. On the contrary, patients with the IMN $\geq 1.0 \mathrm{~cm}$ might have large IMN tumor burden, which is resistant to moderate dose radiation and contemporary systemic agents. Ineffective control of IMN metastasis might allow spreading of cancer cells to distant organs, thereby resulting in poor DFS. In the meantime, it is probable that the above-mentioned dose-response relationship was resulted from an inequivalent distribution of pathological IMN metastasis between the patients with IMN $<1.0 \mathrm{~cm}$ and those with IMN $\geq 1.0 \mathrm{~cm}$. Even though the number of patients with a positive FNABx was not different between the patients with IMN $<1.0 \mathrm{~cm}$ and those with IMN $\geq 1.0 \mathrm{~cm}$, half of our patients did not have pathologic confirmation of IMN metastasis. Further studies are necessary to accurately interpret the dose-response effect found in the current analysis. The optimal cutoff value of the EQD2 to the IMN was $63.6 \mathrm{~Gy}$ in our study. Given that the 5 -year DFS rate was $69.3 \%$ in patients with IMN size $\geq 1.0 \mathrm{~cm}$ after EQD2 of 63.6-70.4 Gy, there is still room for further improvement. More intensified treatment strategies-such as applying higher IMN radiation doses or administering more effective systemic agents-might be required to achieve better outcomes for patients with large IMN metastasis. In addition, modifying the IMN radiation dose according to the response after neoadjuvant chemotherapy (NAC) can help in optimizing the RT dose for cIMN+ breast cancer [4, 30]. Further studies are necessary to determine the optimal RT regimen for patients with cIMN+ breast cancer.

In our study, we found that patients 40 years old or younger had superior DFS than those of over 40 years of age. Contrary to our finding, previous studies showed that young age is an adverse prognostic factor for survival in patients with breast cancer [31, 32]. Breast cancer in young patients is likely to have more aggressive 
biological features such as high grade or triple-negative subtype as compared to those arising in older patients [31]. In a recent study, young age was significantly associated with increased risk of breast cancer death, but only among patients with luminal type tumor. The negative prognostic effect of young age was not found among patients with TNBC or HER2+ tumor [32]. Likewise, it seems that a worse breast cancer outcome in young patients is linked to the tumor characteristics, not the young age per se. In our study, young patients had a better breast cancer outcome than older patients. Given that tumor characteristics were not different between the age groups in our study (Table 9), other factors might contribute to the worse outcome in the patients > 40 years old. In previous studies on cIMN+ breast cancer, the prognostic impact of the patient's age on breast cancer outcome has not been evaluated $[4,12,25,26$, 28]. Further studies are necessary to determine whether age is significantly associated with survival in patients with cIMN+ breast cancer.

This study has some limitations. The follow-up duration of our patients was short. With a median follow-up time of 58 months, the rate of treatmentrelated toxicity might be underestimated. As the likelihood of radiation-related toxicity, such as cardiac disorder, increases with time after RT, a longer follow-up is necessary to ascertain the incidence of treatment-related adverse events [33, 34]. Moreover, we could not assess the prognostic significance of some variables. Among the patients receiving NAC, information about the histologic grade of the breast tumor and the number of positive ALN was not available when a pathologic complete response was obtained. Furthermore, we could not evaluate the prognostic impact of the NAC response on the outcomes because many of the patients in our study did not receive NAC. To assess prognostic significance of the above-mentioned variables, we have a plan to conduct a multicenter retrospective study including a large number of patients. Despite the limitations, the findings of our study have important implications for determining the optimal radiation dose for the management of cIMN+ breast cancer.

\section{Conclusions}

Patients with cIMN+ breast cancer achieved favorable outcomes after the combined treatment of breast surgery, IMN-targeted RT, and systemic therapy. In patients with IMN size $\geq 1.0 \mathrm{~cm}$, a high IMN radiation dose was significantly associated with improved DFS. Therefore, it might be necessary to administer an EQD2 > 63.5 Gy to the IMN to achieve favorable outcomes in patients with large IMN metastasis from breast cancer.

\section{Abbreviations}

3D-CRT: Three-dimensional conformal radiotherapy; ALN: Axillary lymph node; BCS: Breast conserving surgery; CIMN+: Clinical metastasis to the internal mammary lymph node; CT: computed tomography;

CTCAE: Common terminology criteria for adverse events; DFS: Disease-free survival; EQD2: Biologically equivalent dose in 2 Gy fractions; ER: Estrogen receptor; FNABx: Fine needle aspiration biopsy; HER2: Human epidermal growth factor receptor type 2; IHC: Immunohistochemistry; IMN: Internal mammary lymph node; LRRFS: Loco-regional recurrence-free survival; MRI: Magnetic resonance imaging; OS: Overall survival; PET-CT: Positron emission tomography-computed tomography; PFS: Progression-free survival; PR: Progesterone receptor; RT: Radiotherapy; SCN: Supraclavicular lymph node; TNBC: Triple-negative breast cancer; US: Ultrasonography

\section{Acknowledgements}

The first author Yang worked at the department of Radiation Oncology of the Samsung Medical Center from Mach 2015 to February 2019. She is currently working at the department of Radiation Oncology of the Ajou University School of Medicine.

\section{Contributions}

$\mathrm{KY}$ and $\mathrm{HK}$ contributed the design of this study, the analysis and interpretations of the data, and writing the manuscript. DHC and WP contributed the study design and the interpretations of the results. Also, JMN and WKC helped the data analysis. All authors reviewed and approved the final manuscript.

\section{Corresponding author}

Correspondence to Haeyoung Kim.

\section{Funding}

This study was supported by a grant from Ministry of Science and ICT, Republic of Korea (grant number: NRF-2019R1F1A1062069). The funding sources had no involvement in study design, data collection, data analysis, data interpretation, writing of this report, or the decision to submit this article for publication.

\section{Availability of data and materials}

The datasets used and/or analyzed during the current study are available from the corresponding author on reasonable request.

\section{Ethics approval and consent to participate}

This study was approved by the institutional review board of the Samsung Medical Center with No. 2019-02-081, and was classified exempt to obtain informed consent.

\section{Consent for publication}

Not applicable.

\section{Competing interests}

The authors declare that they have no competing interests.

\section{Author details}

'Department of Radiation Oncology, Ajou University School of Medicine, Suwon, South Korea. ${ }^{2}$ Department of Radiation Oncology, Samsung Medical Center, Sungkyunkwan University School of Medicine, 81, Irwon-ro, Gangnam-gu, Seoul, Republic of Korea 06351.

Received: 7 September 2019 Accepted: 9 January 2020

Published online: 03 March 2020

\section{References}

1. Sugg SL, Ferguson DJ, Posner MC, Heimann R. Should internal mammary nodes be sampled in the sentinel lymph node era? Ann Surg Oncol. 2000;7: 188-92.

2. Lacour J, Le M, Caceres E, Koszarowski T, Veronesi U, Hill C. Radical mastectomy versus radical mastectomy plus internal mammary dissection. Ten year results of an international cooperative trial in breast cancer. Cancer. 1983;51:1941-3.

3. Cong BB, Cao XS, Cao L, Zhu H, Yu YS, Yu JM, et al. Internal mammary lymph nodes radiotherapy of breast cancer in the era of individualized medicine. Oncotarget. 2017:8:81583-90. 
4. Zhang YJ, Oh JL, Whitman GJ, lyengar P, Yu TK, Tereffe W, et al. Clinically apparent internal mammary nodal metastasis in patients with advanced breast cancer: incidence and local control. Int J Radiat Oncol Biol Phys. 2010;77:1113-9.

5. Jochelson MS, Lebron L, Jacobs SS, Zheng J, Moskowitz CS, Powell SN, et al. Detection of internal mammary Adenopathy in patients with breast Cancer by PET/CT and MRI. AJR Am J Roentgenol. 2015;205:899-904.

6. Heuts EM, van der Ent FW, Hulsewe KW, von Meyenfeldt MF, Voogd AC. Results of tailored treatment for breast cancer patients with internal mammary lymph node metastases. Breast. 2009;18:254-8.

7. Edge SB, Compton CC. The American joint committee on Cancer: the 7th edition of the AJCC cancer staging manual and the future of TNM. Ann Surg Oncol. 2010;17:1471-4.

8. Haviland JS, Owen JR, Dewar JA, Agrawal RK, Barrett J, Barrett-Lee PJ, et al. The UK standardisation of breast radiotherapy (START) trials of radiotherapy hypofractionation for treatment of early breast cancer: 10-year follow-up results of two randomised controlled trials. Lancet Oncol. 2013;14:1086-94.

9. Common Terminology Criteria for Adverse Events (CTCAE) U. S. Department of Health \& Human Services. Bethesda: National Institutes of Health, National Cancer Institute; 2010.

10. Cahoon AR, Smith BD, Yang WT. Internal thoracic lymphadenopathy in breast Cancer. Radiographics. 2017;37:1024-36.

11. Sabel MS. Chapter 13 - regional Management of Breast Cancer. In: Sabel MS, editor. Essentials of breast surgery. Philadelphia: Mosby; 2009. p. 179-207.

12. Joo JH, Kim SS, Ahn SD, Choi EK, Jung JH, Jeong Y, et al. Impact of pathologic diagnosis of internal mammary lymph node metastasis in clinical N2b and N3b breast cancer patients. Breast Cancer Res Treat. 2017;166:511-8.

13. Dogan BE, Dryden MJ, Wei W, Fornage BD, Buchholz TA, Smith B, et al. Sonography and Sonographically guided needle biopsy of internal mammary nodes in staging of patients with breast Cancer. AJR Am J Roentgenol. 2015;205:905-11.

14. Lee HW, Kim SH. Breast magnetic resonance imaging for assessment of internal mammary lymph node status in breast Cancer. J Breast Cancer. 2016;19:191-8

15. Kinoshita T, Odagiri K, Andoh K, Doiuchi T, Sugimura K, Shiotani S, et al. Evaluation of small internal mammary lymph node metastases in breast cancer by MRI. Radiat Med. 1999;17:189-93.

16. Mack $M$, Chetlen $A$, Liao J. Incidental internal mammary lymph nodes visualized on screening breast MRI. AJR Am J Roentgenol. 2015;205:209-14.

17. Ray KM, Munir R, Wisner DJ, Azziz A, Holland BC, Kornak J, et al. Internal mammary lymph nodes as incidental findings at screening breast MRI. Clin Imaging. 2015:39:791-3.

18. Kim EJ, Kim SH, Kang BJ, Choi BG, Song BJ, Choi JJ. Diagnostic value of breast MRI for predicting metastatic axillary lymph nodes in breast cancer patients: diffusion-weighted MRI and conventional MRI. Magn Reson Imaging. 2014;32:1230-6

19. Kinkel K, Helbich TH, Esserman LJ, Barclay J, Schwerin EH, Sickles EA, et al. Dynamic high-spatial-resolution MR imaging of suspicious breast lesions: diagnostic criteria and interobserver variability. AJR Am J Roentgenol. 2000; 175:35-43.

20. Meier P, Ferguson DJ, Karrison T. A controlled trial of extended radical versus radical mastectomy. Ten-year results Cancer. 1989;63:188-95.

21. Veronesi U, Marubini E, Mariani L, Valagussa P, Zucali R. The dissection of internal mammary nodes does not improve the survival of breast cancer patients. 30-year results of a randomised trial. Eur J Cancer. 1999:35:1320-5.

22. Early Breast Cancer Trialists' Collaborative G, Peto R, Davies C, Godwin J, Gray R, Pan HC, et al. Comparisons between different polychemotherapy regimens for early breast cancer: meta-analyses of long-term outcome among 100,000 women in 123 randomised trials. Lancet. 2012;379:432-44.

23. Burris HA 3rd. Docetaxel (Taxotere) in HER-2-positive patients and in combination with trastuzumab (Herceptin). Semin Oncol. 2000;27:19-23.

24. Ranger A, Dunlop A, Hutchinson K, Convery H, Maclennan MK, Chantler $H$, et al. A Dosimetric comparison of breast radiotherapy techniques to treat Locoregional lymph nodes including the internal mammary chain. Clin Oncol. 2018;30:346-53.

25. Park HJ, Shin $\mathrm{KH}$, Cho KH, Park IH, Lee KS, Ro J, et al. Outcomes of positron emission tomography-staged clinical N3 breast cancer treated with neoadjuvant chemotherapy, surgery, and radiotherapy. Int J Radiat Oncol Biol Phys. 2011;81:e689-95.

26. Noh JM, Kim KH, Park W, Suh CO, Huh SJ, Choi DH, et al. Prognostic significance of nodal involvement region in clinical stage IIIc breast cancer patients who received primary systemic treatment, surgery, and radiotherapy. Breast. 2015;24:637-41.

27. Sachdev S, Goodman CR, Neuschler E, Kalakota K, Cutright D, Donnelly ED, et al. Radiotherapy of MRI-detected involved internal mammary lymph nodes in breast cancer. Radiat Oncol. 2017;12:199.

28. Kim J, Chang JS, Choi SH, Kim YB, Keum KC, Suh CO, et al. Radiotherapy for initial clinically positive internal mammary nodes in breast cancer. Radiat Oncol J. 2019;37:91-100.

29. Network NCC. National Comprehensive Cancer Network Breast Cancer guidelines (version 3.2018). https://www.nccnorg/professionals/physician_ gls/pdf/breastpdf.com. Accessed 10 May 2019.

30. Mak KS, Harris JR. Radiotherapy issues after Neoadjuvant chemotherapy. J Natl Cancer Inst Monogr. 2015;2015:87-9.

31. Azim HA Jr, Partridge AH. Biology of breast cancer in young women. Breast Cancer Res. 2014;16:427.

32. Partridge AH, Hughes ME, Warner ET, Ottesen RA, Wong YN, Edge SB, et al. Subtype-dependent relationship between young age at diagnosis and breast Cancer survival. J Clin Oncol. 2016;34:3308-14.

33. Taylor CW, McGale P, Povall JM, Thomas E, Kumar S, Dodwell D, et al. Estimating cardiac exposure from breast cancer radiotherapy in clinical practice. Int J Radiat Oncol Biol Phys. 2009;73:1061-8.

34. Darby SC, McGale P, Taylor CW, Peto R. Long-term mortality from heart disease and lung cancer after radiotherapy for early breast cancer: prospective cohort study of about 300,000 women in US SEER cancer registries. Lancet Oncol. 2005;6:557-65.

\section{Publisher's Note}

Springer Nature remains neutral with regard to jurisdictional claims in published maps and institutional affiliations.
Ready to submit your research? Choose BMC and benefit from:

- fast, convenient online submission

- thorough peer review by experienced researchers in your field

- rapid publication on acceptance

- support for research data, including large and complex data types

- gold Open Access which fosters wider collaboration and increased citations

- maximum visibility for your research: over $100 \mathrm{M}$ website views per year

At BMC, research is always in progress.

Learn more biomedcentral.com/submissions 